\title{
Does Obesity Make an Influence on Surgical Outcomes Following Lumbar Microdiscectomy?
}

\author{
Min-Wook Yoo, Seung-Jae Hyun, Ki-Jeong Kim, Tae-Ahn Jahng, Hyun-Jib Kim \\ Department of Neurosurgery, Spine Center, Seoul National University Bundang Hospital, \\ Seoul National University College of Medicine, Seongnam, Gyeonggi, Korea
}

Objective: The purpose of this study was to evaluate the effect of patients' bod mass index (BMI) on surgical outcomes following one-level lumbar microdiscectomy.

Methods: From June 2003 to March 2007, 129 patients underwent one-level lumbar microdiscectomy performed at a single institution. We divided the patients into 3 groups, depending on BMl. A retrospective study was conducted among the 3 groups. The operation time, estimated blood loss (EBL), postoperative hospital day, recurrent disc herniation, intraoperative durotomy, and postoperative epidural steroid injection were analyzed. Regression models were used to predict the relationship between $\mathrm{BMl}$ and surgical outcomes including operation time and EBL

Results: As BMI is greater, as the operation time is longer and the EBL is more. In particular, linear regression model analysis implied that 2.35 minute in the operation time is longer and $8.89 \mathrm{cc}$ in EBL is more, as BMl of $1 \mathrm{~kg} / \mathrm{m}^{2}$ is increased. No statistically relevant differences were observed for postoperative hospital day, recurrent disc herniation, intraoperative durotomy, and postoperative epidural steroid injection.

Conclusion: The operation time and EBL was significantly increased in obesity, but there were no differences in surgical outcomes. Our results demonstrated that higher BMl are not likely to encounter heightened morbidity in lumbar microdiscectomy.

Key Words: Obesity $\cdot$ Lumbar discectomy $\cdot$ Operation time $\cdot$ Blood loss

\section{INTRODUCTION}

Spinal surgery in obese patients often poses challenges not only to proper patient positioning, but also to obtaining adequate surgical exposure and frequently leads to increased complexity of the procedure and risk for the patient. The excessive subcutaneous fat deposition in obese patients group can be daunting with regard to the surgical approach to the bony structures of the spine ${ }^{3)}$. The general rule has been to increase the length of the incision to allow adequate visualization at depth ${ }^{7}$. The additional tissue injury associated with an increase in incision length and depth is likely a factor in

- Received: May 7, 2014 • Revised: June 11, 2014

- Accepted: June 13, 2014

Corresponding Author: Seung-Jae Hyun, MD, PhD

Department of Neurosurgery, Spine Center Seoul National University Bundang

Hospital, 166 Gumi-ro, Bundang-gu, Seongnam, 463-707, Korea

Tel: +82-31-787-7164, Fax: +82-31-787-4097

E-mail: neurospine@snubh.org

(This is an Open Access article distributed under the terms of the Creative

Commons Attribution Non-Commercial License (http://creativecommons.org/

licenses/by-nc/3.0/) which permits unrestricted non-commercial use, distribution,

and reproduction in any medium, provided the original work is properly cited. the operative site morbidity ${ }^{6}$. Therefore, the operation has been associated with increased operation time, blood loss, wound infection, and other many perioperative complications ${ }^{10}$. But, whether or not the body mass index (BMI) affects the surgical outcomes in obese patients is unclear and forms the basis of this study. We retrospectively analyzed a consecutive series of lumbar microdiscectomies performed in a single center with a minimum 6-month follow-up. Our focus was the effect of patients' BMI on one- level lumbar microdiscectomy. The hypothesis of the study was that obese patients would have worse outcomes than nonobese patients.

\section{MATERIALS AND METHODS}

This is a retrospective single center study. We analyzed all patients who underwent one-level lumbar microdiscectomy performed at our institution between June 2003 and March 2007. Indications for surgery were intractable pain that had not responded to conservative management for 6-8 weeks and intervertebral disc herniation with compression of nerve root confirmed by magnetic resonance imaging. Exclusion criteria included malignancy, trauma, congenital disease, and infection. 
The hospital charts from these patients were reviewed and each patient's BMI was calculated. Patients with a history of previous lumbar spinal surgery, with foraminal disc herniation treated with lateral approach were excluded. Patients treated with discectomy using tubular retractors were also excluded because there was the possibility of false interpretation. These patients were not included in the study cohort. Only patients treated with one-level lumbar microdiscectomy were included in the study. A total of 129 patients were included in the study. The minimum follow-up period was 6 months.

Our primary independent variable of interest was BMI. The BMI was based on the patient's height and weight recorded in the patient's chart at the time of the surgery. Patients were classified into three groups, based on their BMI: normal weight, overweight and obesity. As defined by the National Institutes of Health, some with a BMI less than $25.0 \mathrm{~kg} / \mathrm{m}^{2}$ were considered as normal, others with $25.0 \mathrm{~kg} / \mathrm{m}^{2}$ to $29.9 \mathrm{~kg} / \mathrm{m}^{2}$ were overweight, and others with a BMI of $30.0 \mathrm{~kg} / \mathrm{m}^{2}$ or greater were categorized as obese ${ }^{2)}$. Patient demographics included BMI, gender, age, comorbidities, smoking habit, current medications, side of surgery, level of surgery, and time of maximum follow-up. Comorbidities that were considered included: hypertension, diabetes mellitus, and hyperlipidemia. Intake of medications including aspirin, clopidogrel, and cilostazol was checked by chart review. Operation time, estimated blood loss (EBL), postoperative hospital day, recurrence, intraoperative durotomy, and postoperative epidural steroid injection were compared as surgical outcomes for obese, overweight, and normal patients. Operation time and EBL were estimated from anesthesia intraoperative record. The surgery was reserved for patients with new neurological deficits occurring after recurrent disc herniation or persistent radicular symptoms despite nonsurgical management such as oral analgesia, physical therapy, and epidural steroid injections.

To adjust for statistically significant demographic differences and surgical outcomes among groups, analysis of variance was

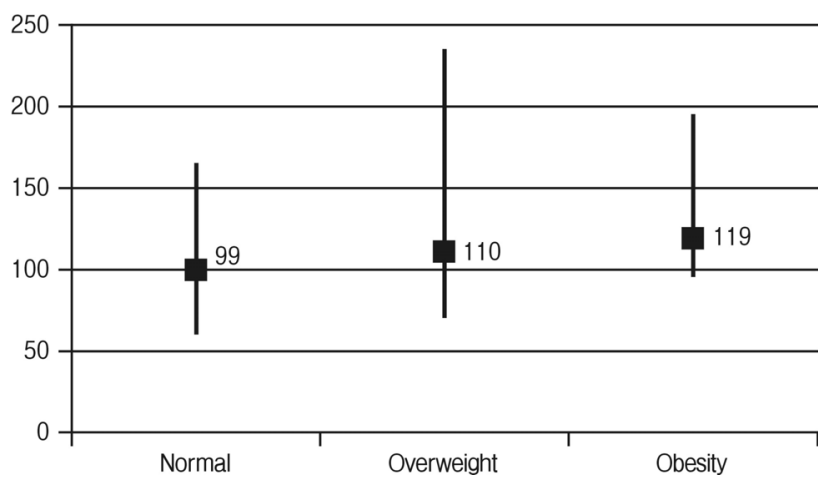

Fig. 1. Average operation time stratified by body mass index. used to evaluate differences in non-continuous variables, whereas the regression analysis was used to assess differences in continuous variables. To evaluate factors potentially impacting the operation time and EBL, a multivariate logistic regression analysis was performed for dependent variables. Covariates analyzed were gender, age, comorbidities, current medications, smoking habit, level or side of surgery, and duration of follow-up. Significance was defined as p-value less than 0.05 on the basis. Data analysis was conducted using SPSS version 21.0 (SPSS Inc., Chicago, IL, USA).

\section{RESULTS}

In this study, 129 patients were enrolled in this study among patients who underwent one-level lumbar microdiscectomy. Demographic and descriptive characteristics of the study cohort are presented in Table 1. Of these, over half of the patients $(57.4 \%)$ were normal $(n=74), 34.9 \%$ were overweight $(\mathrm{n}=45)$, and $7.8 \%$ were obese $(\mathrm{n}=10)$. The normal group was composed of 42 males and 32 females. The overweight group was composed of 26 males and 19 females. And, the obesity group was composed of 6 males and 4 females. Mean age was 49.4 years (range: 20-78 years) for normal patients, 52.9 years (range: 19-76 years) for overweight patients, and 41.7 years (range: $16-78$ years) for obese patients. The normal patients, $27.0 \%$ were smokers. The overweight patients, $15.6 \%$ and obese patients, $30.0 \%$ were smokers. The incidence of hypertension, diabetes mellitus, and hyperlipidemia was respectively $23.0,13.5 \%$, and $6.8 \%$ in normal patients. Correspondingly, the incidence was $31.1,8.9,6.7 \%$ in overweight patients. The incidence was 30.0, 10.0, $0 \%$ in obese patients. Intake of aspirin was noted in $10.8 \%$ of normal patients, $11.1 \%$ of overweight patients, and $30.0 \%$ of obese patients. In all groups, discectomy was mainly made on the left side. The most common spine level operated on was L4-L5 in all groups. We performed multivariate analyses based on patients' gender, age, comorbidities, current medications, smoking habit, level or side of the surgery, and follow-up duration. There were no significant differences in the demographic characteristics among the groups.

The distribution of surgical outcomes for patients' BMI is presented in Table 2 . The average operation time was significantly longer in the obesity $(99.3 \mathrm{~min}$ in the normal group, $110.2 \mathrm{~min}$ the overweight group, and $119.0 \mathrm{~min}$ in the obese group; Fig. 1). The average EBL was also increased in the obesity $(85.2 \mathrm{cc}$ in the normal group, $116.1 \mathrm{cc}$ in the overweight group, and $177.5 \mathrm{cc}$ in the obese group; Fig. 2). This confirmed the statistically significant association between obesity and surgical outcomes, including operation time and EBL. 
Table 1. Demographic information about the study population

\begin{tabular}{|c|c|c|c|c|}
\hline & & BMI $\left(\mathrm{kg} / \mathrm{m}^{2}\right)$ & & \\
\hline $\begin{array}{c}\text { Demographic } \\
\text { characters }\end{array}$ & $\begin{array}{c}\text { Normal } \\
(15.0-24.9) \\
\mathrm{N}=74\end{array}$ & $\begin{array}{c}\text { Overweight } \\
\begin{array}{c}(25.0-29.9) \\
N=45\end{array}\end{array}$ & $\begin{array}{c}\text { Obesity } \\
(30.0-39.9) \\
\mathrm{N}=10\end{array}$ & $p$-value \\
\hline Gender & & & & 0.979 \\
\hline Men & 42 & 26 & 6 & \\
\hline Women & 32 & 19 & 4 & \\
\hline Age $(y r)$ & 20-78 (mean:49.4) & 19-76 (mean:52.9) & 16-78 (mean:41.7) & 0.087 \\
\hline \multicolumn{5}{|l|}{ Comorbidities } \\
\hline Hypertension & 17 (23.0\%) & 14 (31.1\%) & 3 (30.0\%) & 0.604 \\
\hline $\mathrm{DM}$ & $10(13.5 \%)$ & $4(8.9 \%)$ & 1 (10.0\%) & 0.742 \\
\hline Hyperlipidemia & $5(6.8 \%)$ & $3(6.7 \%)$ & 0 & 0.704 \\
\hline Smokers & 20 (27.0\%) & $7(15.6 \%)$ & 3 (30.0\%) & 0.316 \\
\hline \multicolumn{5}{|l|}{ Medication } \\
\hline Aspirin & 8 (10.8\%) & 5 (11.1\%) & 3 (30.0\%) & 0.217 \\
\hline Clopidogrel & $3(4.1 \%)$ & 0 & 0 & 0.325 \\
\hline Cilostazol & 0 & 0 & 0 & \\
\hline Side of surgery & & & & 0.646 \\
\hline Left & 38 & 22 & 6 & \\
\hline Right & 36 & 21 & 4 & \\
\hline Bilateral & 0 & 2 & 0 & \\
\hline Level of surgery & & & & 0.800 \\
\hline L1-2 & 1 & 1 & 1 & \\
\hline L2-3 & 4 & 2 & 0 & \\
\hline L3-4 & 4 & 3 & 0 & \\
\hline$\lfloor 4-5$ & $43(58.1 \%)$ & $26(57.8 \%)$ & 7 (70.0\%) & \\
\hline L5-S1 & $22(29.7 \%)$ & $13(28.9 \%)$ & $2(20.0 \%)$ & \\
\hline Follow-up (mo) & 6-122 (mean:41) & 7-125 (mean:46) & 7-82 (mean:42) & 0.703 \\
\hline
\end{tabular}

Table 2. Multiple regression analysis of outcomes stratified by body mass index

\begin{tabular}{|c|c|c|c|c|c|c|}
\hline \multirow[b]{2}{*}{ Surgical outcomes } & \multicolumn{3}{|c|}{ BMI $\left(\mathrm{kg} / \mathrm{m}^{2}\right)$} & \multirow[b]{2}{*}{$\mathrm{p}$-value } & \multirow[b]{2}{*}{$\beta^{*}$} & \multirow[b]{2}{*}{$95 \% \mathrm{Cl}$} \\
\hline & $\begin{array}{c}\text { Normal } \\
(15.0-24.9) \\
\mathrm{N}=74\end{array}$ & $\begin{array}{c}\text { Ovenweight } \\
(25.0-29.9) \\
\mathrm{N}=45\end{array}$ & $\begin{array}{c}\text { Obesity } \\
(30.0-39.9) \\
\mathrm{N}=10\end{array}$ & & & \\
\hline Operation time (min) & $\begin{array}{c}60-165 \\
\text { (mean:99.3) }\end{array}$ & $\begin{array}{c}70-235 \\
\text { (mean: 1 10.2) }\end{array}$ & $\begin{array}{c}\text { 95-195 } \\
\text { (mean:119.0) }\end{array}$ & 0.004 & 2.354 & $0.768-3.940$ \\
\hline Estimated blood loss (ml) & $\begin{array}{c}0-1,000 \\
\text { (mean:85.2) }\end{array}$ & $\begin{array}{c}0-600 \\
\text { (mean: } 116.1)\end{array}$ & $\begin{array}{c}0-900 \\
\text { (mean: 177.5) }\end{array}$ & 0.014 & 8.889 & $1.843-15.943$ \\
\hline Postoperative hospital day & $\begin{array}{c}3-31 \\
\text { (mean:6.9) }\end{array}$ & $\begin{array}{c}2-23 \\
\text { (mean:7.4) }\end{array}$ & $\begin{array}{c}3-12 \\
\text { (mean:6.5) }\end{array}$ & 0.349 & & \\
\hline Recurrent disc herniation & 12 (16.2\%) & $9(20.0 \%)$ & $1(10.0 \%)$ & 0.901 & & \\
\hline Intraoperative durotomy & $4(5.4 \%)$ & 4 (8.9\%) & 1 (10.0\%) & 0.414 & & \\
\hline Postoperative steroid injection & 22 (29.7\%) & $20(44.4 \%)$ & $1(10.0 \% 0$ & 0.590 & & \\
\hline
\end{tabular}

$\beta^{*}$ : Coefficient

$\mathrm{Cl}$ : Confidential interval

As $\mathrm{BMI}$ is greater, as the operation time is longer $(\mathrm{p}=0.004$, the relationships between $\mathrm{BMI}$ and surgical outcomes includbeta $=2.354)$ and the EBL is more $(\mathrm{p}=0.014$, beta $=8.889)$. ing operation time (Fig. 3) and EBL (Fig. 4). This implies that In particular, linear regression models were used to predict 2.35 minute in the operation time is longer and $8.89 \mathrm{cc}$ in 


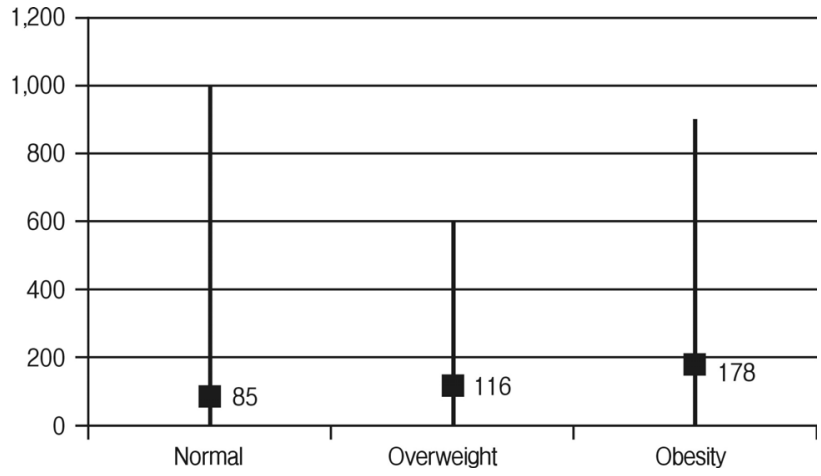

Fig. 2. Averatge estimated blood loss stratified by body mass index.

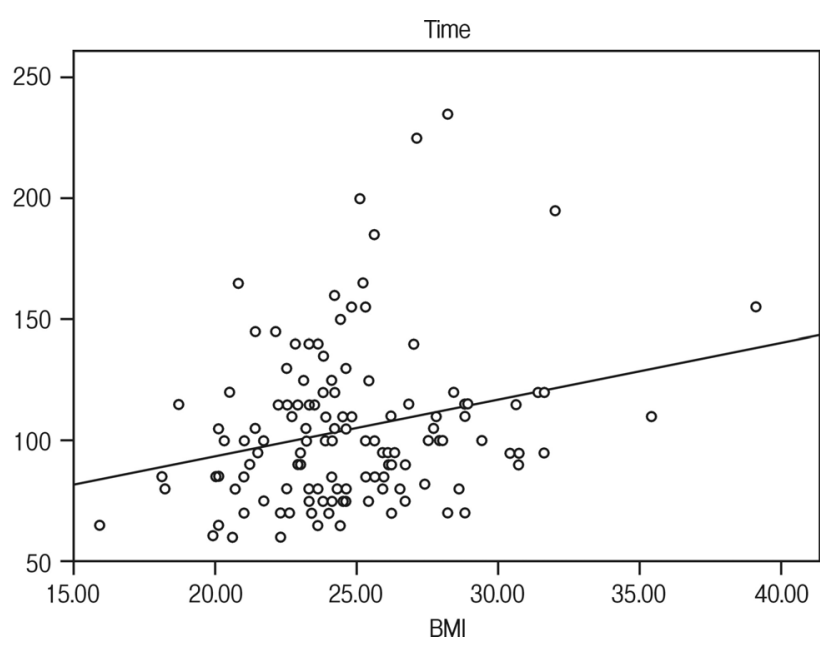

Fig. 3. Linear regression model of operation time for body mass index.

EBL is much more, as BMI of $1 \mathrm{~kg} / \mathrm{m}^{2}$ is increased. No substantial clinically relevant differences were observed for mean postoperative hospital day (6.9 days in normal group, 7.4 days in overweight group, and 6.5 days in obese group). Of our patients who had microdiscectomy, 22 had reoperation for recurrent disc herniation (17.1\%). 9 intraoperative durotomies occurred (7.0\%). Forty three patients have required postoperative epidural steroid injection (33.3\%). No patients had a postoperative infection. There were no significant differences in other surgical outcomes, including postoperative hospital day $(\mathrm{p}=0.349)$, recurrent disc herniation $(\mathrm{p}=0.901)$, intraoperative durotomy $(\mathrm{p}=0.414)$, and postoperative epidural steroid injection $(\mathrm{p}=0.590)$ among the groups.

To determine the risk factors of operation time and EBL, among clinical characteristics, a regression analysis was done. Multivariate regression analysis demonstrated that women $(\mathrm{p}=$ 0.026 , beta $=14.389)$ and hypertension $(p=0.002$, beta $=18.788)$ were significant factors for operation time. Analysis for EBL showed that high level surgery $(\mathrm{p}=0.049$, beta $=-31.620)$ had

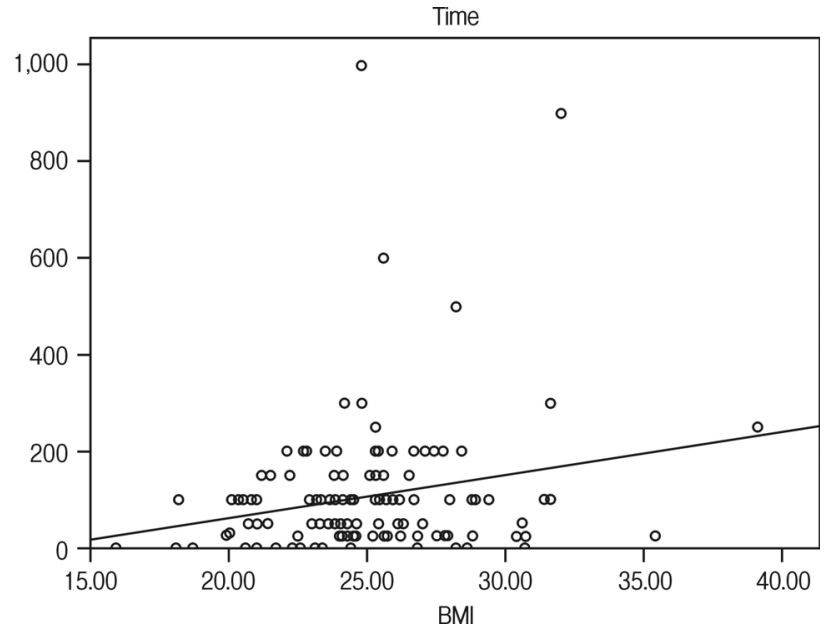

Fig. 4. Linear regression model of estimated blood loss for body mass index.

more bleeding risk compared with low level surgery. None of the other variables demonstrated a significant association with operation time and EBL.

\section{DISCUSSION}

Spine surgery in the obese is a challenging endeavor for many reasons, including anesthetic considerations, intravenous access, and positioning, as well as the procedure itself $f^{9)}$. Lumbar microdiscectomy usually involved a longer incision than usual in obese patients ${ }^{11)}$. Retraction was difficult and visualization of the important elements of the operation was obscured by the patient's depth ${ }^{4)}$. This study was performed to evaluate outcomes after lumbar microdiscectomy in patient who are obese. Although obesity has been shown to result in longer operation time and more intraoperative bleeding, it was not clear from previous reports if the surgical outcomes were dependent on the degree of obesity. A previous study comparing perioperative findings between obese and nonobese patients undergoing lumbar spine surgery demonstrated no difference in operation time, EBL, or length of hospital day ${ }^{1)}$. But, other study by Jeffrey et al. demonstrated that obesity leads to increased operation time, EBL, and length of hospital day ${ }^{8}$.

We retrospectively investigated the effect of patients' BMI on surgical outcomes. We found a statistically significant difference in the operation time and EBL of obese patients compared with normal those. The coefficient for patients with a BMI above $25 \mathrm{~kg} / \mathrm{m}^{2}$ was highly significant in the operation time and EBL. Our study found that overweight or obese patients had a longer operation time and more intraoperative bleeding. But, there were no differences in surgical outcomes including postoperative hospital day, recurrent disc hernia- 
tion, intraoperative durotomy, and postoperative epidural steroid injection. Our results demonstrated that higher BMI might be not related with heightened morbidity in lumbar microdiscectomy. Other factors associated with longer operation time and more intraoperative blood loss were found in multivariate regression analysis. Gender, hypertension, and level of surgery also made an influence on the operation time and EBL. In this study, woman and hypertension were found to be a significant predictor of operation time and level of surgery was a predictor of EBL. Conversely, another researcher reported that male and level of surgery were factors associated more intraoperative blood loss ${ }^{12)}$. The explanation for this difference in findings may be that the present study included patients with lumbar discectomy whereas the previous study evaluated patients with lumbar fusion surgery ${ }^{12}$. This discrepancy warrants further investigation because risk factors to affect surgical outcomes are variable as the type of surgery.

Our recurrence rate was $17.1 \%$. According to this study, the patients didn't show a higher recurrence rate even though with a higher BMI. This finding contradicts other published literature. Previous investigator retrospectively reviewed 75 patients who had undergone a microdiscectomy, 8 (10.7\%) of whom had experienced a recurrent herniation ${ }^{5)}$. They associated obesity with a twelve times higher likelihood of postoperative recurrent herniation and a thirty times higher likelihood of requiring a reoperation and concluded that weight loss counseling should be incorporated in preoperative discussions. However, there was no confidence in reliability of the study, because of their small sample size. In our study which the sample size was larger than the previous study, there were no differences in surgical outcomes. This finding is likely more representative of the general population. Additionally, our data demonstrated that age, current medications, smoking habit, side of the surgery, and follow-up duration are not significant predictors for the operation time or EBL.

The use of a retrospective design from the cases at a single institution is a notable limitation of our study. As a retrospective case series, it has potential biases. The use of a prospective design by future studies would strengthen these findings. The follow-up period ranged from 6 to 125 months with all patients having at least 6 months of follow-up. Another weakness was that this follow-up duration is not extensive enough. In the future study, a longer follow-up period would prove useful and will endeavor to publish long-term results in the patients. In the current study, we could not investigate confounding baseline variables including level of education, income, marital status, and occupation, differed among three groups. These differences may have affected the results of the present study. In total of 129 patients, only 10 patients were obese. The proportion of obesity was too small in the study, which could be a limitation. Finally, the imprecision of BMI as a marker of obesity was another important limitation. Other measures, such as skin-fold thickness or body surface area, may be more specific measures of obesity to include in future studies.

\section{CONCLUSION}

In summary, this analysis doesn't support the hypothesis that patients with higher BMI are likely to encounter heightened morbidity in lumbar microdiscectomy. Although the operation time and EBL was significantly increased in obesity, there were no differences in surgical outcomes including postoperative hospital day, recurrent disc herniation, intraoperative durotomy, and postoperative epidural steroid injection. Based on the results of this study, our results suggested that higher BMI are not likely to encounter heightened morbidity in lumbar microdiscectomy.

\section{ACKNOWLEDGEMENT}

Nothing of value received from a commercial entity is related to this research

\section{REFERENCES}

1. Andreshak TG, An HS, Hall J, Stein B: Lumbar spine surgery in the obese patient. J Spinal Disord 10:376-379, 1997

2. Buerba RA, Fu MC, Gruskay JA, Long WD, $3^{\text {rd }}$, Grauer JN: Obese Class III patients at significantly greater risk of multiple complications after lumbar surgery: an analysis of 10,387 patients in the ACS NSQIP database. Spine J 2013

3. Cole JSt, Jackson TR: Minimally invasive lumbar discectomy in obese patients. Neurosurgery 61:539-544; discussion 544, 2007

4. Mehta AI, Babu R, Karikari IO, Grunch B, Agarwal VJ, Owens TR, et al: 2012 Young Investigator Award winner: The distribution of body mass as a significant risk factor for lumbar spinal fusion postoperative infections. Spine (Phila Pa 1976) 37: 1652-1656, 2012

5. Meredith DS, Huang RC, Nguyen J, Lyman S: Obesity increases the risk of recurrent herniated nucleus pulposus after lumbar microdiscectomy. Spine J 10:575-580, 2010

6. Park P, Upadhyaya C, Garton HJ, Foley KT: The impact of minimally invasive spine surgery on perioperative complications in overweight or obese patients. Neurosurgery 62:693-699; discussion 693-699, 2008

7. Patel N, Bagan B, Vadera S, Maltenfort MG, Deutsch H, Vaccaro $\mathrm{AR}$, et al: Obesity and spine surgery: relation to perioperative complications. J Neurosurg Spine 6:291-297, 2007

8. Rihn JA, Kurd M, Hilibrand AS, Lurie J, Zhao W, Albert T, et al: The influence of obesity on the outcome of treatment of lumbar disc herniation: analysis of the Spine Patient Outcomes 
Research Trial (SPORT). J Bone Joint Surg Am 95:1-8, 2013

9. Shamji MF, Parker S, Cook C, Pietrobon R, Brown C, Isaacs RE: Impact of body habitus on perioperative morbidity associated with fusion of the thoracolumbar and lumbar spine. Neurosurgery 65:490-498; discussion 498, 2009

10. Telfeian AE, Reiter GT, Durham SR, Marcotte P: Spine surgery in morbidly obese patients. J Neurosurg 97:20-24, 2002
11. Tomasino A, Parikh K, Steinberger J, Knopman J, Boockvar J, Hartl R: Tubular microsurgery for lumbar discectomies and laminectomies in obese patients: operative results and outcome. Spine (Phila Pa 1976) 34:E664-672, 2009

12. Vaidya R, Carp J, Bartol S, Ouellette N, Lee S, Sethi A: Lumbar spine fusion in obese and morbidly obese patients. Spine (Phila Pa 1976) 34:495-500, 2009 